\title{
Social Capital of Organizations: From Social Structure to the Management of Corporate Social Capital
}

\author{
Shaul M. Gabbay \\ Roger Th.A.J. Leenders
}

SOM-theme B Innovation and interaction

\begin{abstract}
Social capital in general and the study of social capital in the context of organizations has gained considerable attention in recent years. Despite the promise in the potency of the concept, its useful application suffers from the plethora of different definitions and approaches - both theoretical and empirical. In this paper we build upon one unifying definition and attempt to provide an encompassing framework for corporate social capital — from both a theoretical and empirical point of view. We do this by explicitly distinguishing between social capital and social networks. Moreover, we distinguish between the positive (social capital) and negative (social liability) outcomes of social networks. Finally, we argue that it is imperative to consider the various organizational levels of analysis at which both social relationships and their outcomes (and antecedents) reside.
\end{abstract}

(also downloadable) in electronic version: http://som.rug.nl/ 


\section{Introduction}

Since Auguste Comte coined the term sociology in the $19^{\text {th }}$ century, sociological thought has focused on 'man and his social context.' The works of Durkheim and Simmel focused sociological attention to forms of social interaction (Simmel, 1950; 1955) and social structural determinants of human behavior (Durkheim, 1950; 1951). The formal and structural approaches in sociology also provide the basis for how modern network students view social structure. The study of social networks has proliferated for over three decades. Over the last thirty years, network research has focused on the social structural patterns that characterize human interaction. Social structure, then, is seen as a network of actors who are in some way connected through a set of relationships (Gabbay and Leenders, 1999: 1). Especially the nineteen seventies and eighties experienced a cascade of network research with a descriptive focus - the main research goal being to debunk common social structures and their characteristics. This approach was static, descriptive, and classifying - it provided most of the well-known descriptive network measures used in network research today. Later, attention shifted to how networks arise and change over time. This approach has given rise to dynamic, exploratory, and explanatory research. The recent three decades have supplied the field of network study with thorough methodology for the study of man in his social environment (see Burt, 1982; Coleman, 1988, Krackhardt, 1988, Knoke, 1999) and have given rise to methods that assist in mapping, tracking, and deconstructing data on network structures (Wasserman and Faust 1994; Leenders 1995ab).

\section{Social Capital and Network Theory}

Although network studies became greatly popular in the 80 's, they have not been encompassed by a unifying theory in which the accumulated empirical results can be placed (Granovetter, 1985; Salancik, 1995). A strong call has been made for 'a good 
network theory of organization' suggesting that 'a network theory of organization should propose how structures of interactions enable coordinated interaction to achieve collective and individual interests' (Salancik 1995: 348). In the 90's, the concept of social capital gained prominence as a potential answer to this call — in research both focusing on the study of organizations as well as other areas of interest - and has since been adopted by many network scholars. Social capital has grounded the discourse of social networks in a focus on the productive outcomes associated with social structures/social networks. The seminal works of Coleman (1990), Burt (1992), and Putnam (1993) pioneered the concept of social capital in the social sciences. Social capital has since gained increasing attention in a variety of disciplines and schools of thought, such as economics, political science, management studies, and, in particular, in sociology (for extensive reviews see Portes and Sensenbrener, 1993; Woolcock, 1998; Adler and Kwon 2000).

Nevertheless, despite the popularity of the concept, social capital has not been uniformly defined (see Burt, 2000 for a discussion). For instance, Coleman refers to social capital as 'some aspect of a social structure...facilitating certain actions of individuals who are within the structure... social capital is productive, making possible the achievements of certain ends...' (1990:302). Burt (1992), on the other hand defines social capital as 'social structure which confers advantage.' In Burt's view, social capital and social structure are two sides of the same structural coin and social capital is not necessarily connected to explicit goals of actors in this structure. Bourdieu, on the other hand, defines social capital as 'the aggregate of the actual or potential resources that are linked to a possession of a durable network of more or less institutionalized relationships of mutual acquaintance and recognition ... a 'credential' which entitles them to credit, in the various senses of the word' (Bourdieu 1986: 249). In Bourdieu's understanding of the term, social capital refers to the outcomes of the social structure, rather than to (the elements in) the structure itself and is potentially irrespective of the explicit and active pursuit of goals by an actor. 


\section{The Social Structure of Social Capital}

The challenge of arriving at an accepted and useable general definition of social capital has been so critical in the social capital discourse, that some scholars have suggested that social capital may be at a risk of being used as a metaphor per se (Burt, 2000). Many scholars have taken up this challenge by attempting to distinguish various social structures that bring advantages to actors. When such structures can be uncovered and classified, it becomes possible to differentiate between social structure on the one hand and social structure and social capital on the other. Through this lens, social capital studies can be seen as a subset of the study of social networks. Figure 1 presents the typology for the studies in the field.

\section{(figure 1 here)}

Studies of social structure as social capital can be categorized by the distinction between the 'tie approach' and the 'structural form' approach (Gabbay, 1997). Theories that belong to the 'tie approach' school focus on the dyadic relationships between a given ego and a given alter. Within this approach, ego draws a benefit from a resourceful alter-for instance, by means of the status of an alter (Lin et al., 1981ab; Marsden and Hurlbert, 1988; De Graaf and Flap, 1988) or through the information alter may offer. Ego may also draw benefits from a resourceful kind of tie - for example, a weak tie may bring information on distinct social circles (Granovetter, 1973) and a strong tie may bring increased trust, prospective reciprocity, and commitment (Krackhardt and Stern, 1988; Uzzi, 1997ab; Gabbay, 1997; Gabbay and Stein, 1999).

The structural form approach focuses on the structure of relationships in which ego is embedded (or tied too) and the kinds of benefits these particular structures are correlated with. For example, closed networks create normative sanctioning mechanisms and, consequently, higher levels of trust (Coleman, 1988, 1990; Putnam, 1993). Social 
structures rich in 'structural holes' create information opportunities and control benefits (Burt, 1992; Burt et al., 1994).

\section{Change over Time of Social Structure}

As we argued above, social network research was long grounded in the tradition of classical structural sociologists such as Simmel and Durkheim. According to this line of thought, social structure is given - human beings are embedded in and constrained by the particular social structure that connects them. For Simmel (1950), triadic forms of network have an external and confining effect independent of the particular actors. For Durkheim (1951), even the most personal intimate action a human being can performsuicide - is determined by the level of interconnectedness within the social context 'sui generi' (be it religion or living in a city versus a village). According to Durkheim, social structure is considered a social fact independent of the individual actors. This perception of the classical structural theories had its undeniable effect on social network and social capital students. Social structure is commonly considered a given and it is this given, static, structure that provides outcomes to actors (such as promotion and social norms). Moreover, most studies that do acknowledge that social structure is subject to change over time, only empirically consider a single snapshot of the social structure and therefore rely on empirical tests associated with a given static structure.

Nevertheless, increasingly networks are seen as dynamic and ever changing. There are two generic reasons why networks change. The first is related to normal, natural change. As actors engage in normal social interaction, relationships are created and broken. Some ties are longer-lived than are other ties. Some actors enter a network and others leave. As a result, social structure does not remain constant over extended periods of time.

The second reason why networks change relates to purposive action of actors who actively shape and alter the social structure they are embedded in. If networks are determinative of resources and restrictions, it is rational for actors to try and alter the 
distribution of resources and restrictions by changing certain relationships, so as to achieve their individual goals better (Coleman, 1990; Burt, 1992; Leenders, 1995a, Gabbay, 1997; Leenders \& Gabbay 1999a). Alternatively, actors may attempt to 'freeze' favorable social structure, for the purpose of securing future social capital. This freezing process effectively decreases the extent and nature of network change that would occur under non-purposive natural network activity. These considerations turn the agenda from 'structure as a cause' to 'structure as an outcome' (Gabbay, 1997). Within this agenda, network change is not seen as a by-product of normal social interaction, but also as being governed by strategic behavior of actors. The term 'Social Capital Management' (Leenders and Gabbay, 1999b: 491) describes this purposive change. The 'structure as outcome' approach not only invokes a different mindset for the study of social capital and social structure, but it also requires the development of additional network methodology for studying networks over time and their temporal association with outcomes (e.g., Wasserman \& Faust 1994; Zeggelink 1994; Leenders 1995ab, 1997; Gabbay 1997; Snijders 1996).

It is important to note that we do not suggest a preference for the study of 'structure as outcome' over the study of 'structure as a cause' (or vice versa). Instead, we argue that both approaches are equally essential if the intention is to understand network behavior and network effects (see Figure 2). The view of 'structure as a cause' focuses on the positive and negative effects that networks have on the actors comprising the network. Alternatively, 'networks as an outcome' focuses on the way in which actors deal with network circumstances and adapt (or, consolidate) their ego network in order to secure and improve future favorable results.

(Figure 2 here) 


\section{Social Capital and Social Liability}

From the distinction between 'networks as a cause' and 'networks as an outcome,' it becomes apparent that we make an explicit distinction between social structure and social capital. Like other forms of capital, social capital is productive, making possible the achievement of goals that would not be attainable in its absence (Coleman 1990). This goal specificity has a number of implications. First, social structure can be beneficial for the attainment of multiple goals, since the multiplex character of many social relationships results in overlap of opportunity structures. Networks created for one purpose may be employed for another-which often was not foreseen when the actors initially engaged in their relationships. In some situations, the same social structure can be beneficial for the attainment of one goal, while obstructing the attainment of others. For example, social networks can have the positive effect of providing network members with access to privileged resources, while lowering transaction costs. However, at the same time the social network may place high demands on members in these networks and restrict their individual behavior and opportunities.

Although social structure and social capital are often equated in the social capital literature, they are different entities. We therefore make an explicit distinction between social structure per se and the outcomes of social structure. When these outcomes are positive, helpful in attaining specific goals, the social structure is said to convey social capital. When social structure prohibits and obstructs action, it produces social liability. For example, Leenders (1995a) showed that relations among social service workers can help in preventing them from burnout, but that feelings of burnout are also contagious through these exact same relationships: increases in burnout experienced by social service workers increased the level of burnout experienced by their co-workers. Conversely, decreasing levels of burnout led to decreasing levels among alters. The same social structure would thus convey the social liability of increasing burnout in alters when ego becomes more burnt out, and bring social capital in the form of decreasing burnout among alters when ego becomes less burnt out. 
Hansen et al. (2001) document the contingency aspects of social capital in the context of product development units. Social structures of product development teams yield social capital in some task situations but convey social liability in others. In their research, network position that conveyed social capital for teams engaged in exploration tasks was found to be a social liability for teams pursuing exploitation tasks. Exploratory teams completed their projects more quickly if they had a social network structure composed of many strong external ties that were non-redundant. In contrast, teams pursuing tasks that exploited existing expertise took longer to complete if they had this type of social network structure, mainly because external ties had to be maintained but were not much needed for the task.

Although the absence of social structure precludes social capital from coming into existence, the two are distinct. This distinction directly feeds back onto the previous discussion of change over time in network structure. Social structure that provides social capital in the present may not necessarily do so in the future. The social structure essential to sustain social capital may shift as transactions, activities, and conditions change and become more or less complex. Relationships beneficial to the achievement of goals in the past may thwart goal attainment in the future. Studying how managers adapt to changing environmental conditions, Gargiulo and Benassi (1999) showed that relational structures that were helpful to these managers in the past, later increased the number of coordination failures for which these managers were responsible. The network no longer provided resources, but had become a constraint, impeding their performance. In his study on network marketing, Gabbay (1997) found that, for some actors, strong ties combined with structural holes were beneficial at the initial stages of their business, but were harmful for future expansion. Successful entrepreneurs strategically changed their networks over time in order to build or maintain those social structures that yielded social capital.

Social structure translates into social liability in at least two different ways. First, ongoing, strong social relationships may constrain the behavior of actors, impeding their 
action and attainment of goals. For example, long-standing relationships with customers may stifle a firm by monopolizing a disproportionate share of its resources, inhibiting the firm to form relationships with alternative customers. Second, actors may be unfavorably affected in their opportunities by negative ties in the social structure. For example, Brass and Labianca (1999: 324) argue that 'it is likely that an actor's negative ties within an organization will prevent promotion, particularly if those negative relationships are with influential others. Others may withhold critical information that worsens an actor's performance or they may provide bad references in order to prevent a promotion.'

Organizations and their members continuously engage in social relationships. Effective organization demands a constant balancing of the potentially opposing forces inherent in social structures.

\section{From Social Capital of Individuals to Corporate Social Capital}

While studies of social capital have traditionally focused on the individual as the unit of analysis - 'man in his social context' - the study of Burt (1992) has been instrumental in suggesting the organization as a context for social capital research. Since the publication of his book 'Structural Holes,' much research has been performed on networks in organizations (see, for instance, the collection of papers in Nohria and Eccles, 1992).

Although the research of Burt and his students shifts the focus to the context of organizations, the unit of analysis remains the individual within an organization. Much of the organizational social capital literature has an individual slant, with firm attributes examined as an individual manifestation. In 'Corporate Social Capital and Liability' (Leenders and Gabbay, 1999a) it is suggested that organizations themselves are actors embedded in social structure and that they enjoy the benefits and suffer from the obstacles that this social structure brings. Accentuating their focus on social capital in and of organizations, rather than on only studying social capital of the individuals within an 
organization, they employ the term corporate social capital, defined as (Gabbay \& Leenders 1999: 3):

The set of resources, tangible or virtual, that accrue to a corporate player through the player's social relationships, facilitating the attainment of goals.

with 'corporate players' referring to organizations and their members.

When social structure benefits corporate players in the attainment of their goals, social structure is said to convey 'corporate social capital,' when it obstructs them it brings 'corporate social liability.' This is the definition adhered to also in this paper.

\section{Levels of Analysis}

The distinction between social structure per se and the outcomes of social structure highlights the requirement of an explicit focus on levels of analysis in any social capital study. This requirement is especially paramount for studies of social capital in organizational settings. The social capital that individual employees enjoy stems both from their own networks (and the networks of their alters) and from the networks within and between teams, departments, and companies. For example, an engineer who is a member of a product development team can accumulate required knowledge through his team mates (network at the individual level), but can also build on knowledge that is created in other teams and is spread across teams (for example, through the use of glass walls or intra-nets). Similarly, this engineer can enjoy the social capital of international career opportunities by making use of the alliance network maintained by his organization. In this example, the social capital offered to the engineer thus results from the social structure at the individual level, at the team level, and at the organizational level. In like manner, the organization benefits from both its interorganizational network, and from the flow of knowledge between subsidiaries, departments, teams, and individuals. Social capital and liability trickle up and down these various levels of analysis. 
The distinction between the various levels of analysis can be made in a number of ways and depends on the eye of the beholder. Since many relationships between organizations are played out or mediated by individuals, one can support the argument that such interorganizational networks should be placed at the individual level rather than at the organizational level. For example, the business transaction between an Israeli software firm and a Palestinian manufacturer of vending machines can be seen in two ways. First, as a transaction between the two respective representatives of both companies - the fact that this given software-developing firm enters into business with this particular vending machine company is then solely a result of the personal relationships between these two individuals. Alternatively, it can be seen as a transaction between the companies themselves, regardless of the particular representatives involved. In the former case, different businesses would have entered into a relationship if the affiliations of the two individuals had been different, in the latter case this would not have made a difference. Notwithstanding the upsurge in the number of impersonal computermediated contacts that companies engage in, most business transactions of importance are still carried out between individuals and are based on interpersonal trust building. However, this does not mean that these transactions should necessarily be categorized as a function of the network at the individual level. For example, firms are tied to each other through trade associations, business groups, consortia, cartels, joint ventures, and interlocking directorates. They are locked into licensing agreements and long term supplier-buyer arrangements. Boeing's 747 aircraft requires the input from numerous contractors and sub-contractors - only parts of the cockpit and wings are developed and produced by Boeing. Such inter-firm transactions result in long term links that become institutionalized and independent of the members who created them originally. The business tie between the Israeli and Palestinian firms may still exist long after the two individuals who originally formed the tie are no longer working in these firms (cf. Gabbay and Stein, 1999). Many firms occupy positions in the value chain with interdependencies so dense that one might even consider the value chain to be a more 
salient unit of action than the firms that exist within the value chain (Pennings and Lee 1999).

Despite the sometimes arbitrary (number of) levels of analysis and boundaries between distinguished levels, it is clear that outcomes (capital and liability) at any given level of analysis are a function of structures at multiple levels. Likewise, structure at any given level will typically affect outcomes at multiple levels (See Figure 3).

(figure 3 here)

In fact, the association between structure and outcomes at various levels of analysis goes beyond this. If corporate players can alter structures in order to bring them more social capital, the quest for outcomes at a given level of analysis by a corporate player is likely to lead to purposive structural changes at multiple levels. The interplay between structure and outcomes at multiple levels creates analytical, theoretical, empirical, and methodological issues that are both intricate and challenging. For example, individual 1 in team A may affect individual 2's performance in team B directly through their direct contact, but also indirectly through the network between the teams (see Figure 4). One can only attempt to fully understand the effect of structure on goal attainment of corporate players by explicitly taking into account the various levels of analysis related to structure and outcomes.

\section{(figure 4 here)}

When only two levels of analysis are considered, four types of connections play a role: outcomes at the individual level are created by structures at both the individual and organizational level, and outcomes at the organizational level stem from structures at both levels as well. In Figure 5 we name these four types of connections Types A, B, C, and D. For ease of exposition, we have collapsed the levels of analysis that go beyond the 
individual (such as teams, departments, organization) into one level called 'organizational.' Moreover, in the Figure we only consider 'social structure as a cause' and leave 'social structure as an outcome' (which is an additional dimension) for future and other discussions.

(figure 5 here)

\section{Social Capital and Liability at the Individual Level (Types A and B)}

Type A refers to the lion's share of network studies performed in organizational settings. Social structure and social capital are both considered at the level of the individual. The study of Burt (1992) is typical for this line of studies, showing that managers with disconnected networks achieve faster promotions to managerial positions. Other typical examples include studies on how people mobilize their array of direct and indirect relationships to accomplish personal goals such as finding jobs and achieving upward mobility (e.g., Granovetter, 1973; 1982; Boxman et al. 1991; Flap and Boxman 1999; Lin et al., 1981ab).

Type B refers to situations where networks of corporations confer advantages to individuals. Examples include joint research and development projects between two firms that create new job opportunities for the individuals working in these positions or that produce the knowledge necessary to do one's job better. The politics involved in the interorganizational network may also make the accomplishment of one's job more difficult or even impossible, bestowing the individual with social liability.

\section{Social Capital and Liability at the Firm Level (Types C and D)}

Whether based on networks of individuals or networks of firms, in research regarding types $\mathrm{C}$ and $\mathrm{D}$ the focus is on the benefits or liabilities at the organizational level. 
Type $\mathrm{C}$ refers to the benefits the organization draws from networks of individuals. For example, trustworthy relationships between employees of a firm and the employees of a bank may make it easier for that firm to secure a loan (Mizruchi and Fein, 1999). Law firms, accounting firms, and consulting agencies considerably draw upon the networks partners maintain with their clients. In a recent work, Hansen et al. (2001) specifically looked at networks of individuals in product development settings and how these relationships positively and negatively effect performance at the organization level. Using the distinction between exploration and exploitation tasks, they show that the network position that conveyed positive social capital for teams engaged in exploration tasks is a social liability for teams pursuing exploitation tasks.

Another example for Type C research is given Greve and Saloff's (2001) investigation in the role of social capital in innovation projects. Greve and Saloff describe the use of technical advice relationships among participants in the development of Norwegian offshore oil industry. Their findings show that employees of firms are embedded in multiplex social systems, which provide access to complementary resources. Employees from different firms who were connected in a network of relationships affected the success rate of complex innovative tasks creating corporate social capital for their own firms.

Networks of individuals can also create social liability to the organization. For example, Kratzer et al. (1998) show that segmentation of the problem-solving network among members of R\&D teams is detrimental to the performance of the team, an effect especially strong for teams performing tasks of high complexity. Grapevines-informal, person-to-person communications network of employees, which are not officially sanctioned by the organization - are sources of rumors and gossip that spread quickly throughout an organization. Often, management decisions travel through grapevines days ahead of their official announcement (Davis and Newstrom 1985; Simmons 1985; Hyatt 1989). Because they feel threatened by it, managers often try to suppress the grapevine, but find themselves confronted with a nearly impossible exercise. Another source of 
potential organizational social liability is related to the resilience of personal networks. Managers in charge of (re)designing business processes often experience difficulties in breaking through the power structures that exist between the firm's employees. As a result, many attempts to redesign organizational processes fail or can only be implemented after long and painful struggles between higher management and employees.

Another recent example of the contingent quality of social capital and liability is provided by the study of Johanson (2001). His findings show how social networks enable employees to gain control and information benefits. Employing the distinction between closed structures and structures rich in structural holes - structures than can theoretically be argued to provide favorable outcomes - his discussion shows that social capital might not be realized due to unfavorable contextual factors (cf. Gabbay and Zuckerman, 1998). For example, his findings indicate that sparse social networks might be most beneficial to a bureaucratic organization while cohesiveness does not automatically induce commitment if it is not supported by favorable social norms. The conclusions from this study suggest that when prerequisites of social interaction are not well secured, the organization faces the risk of inadequate levels of social cohesion.

An alternative example of this type of research, Lazega (1999) looks at corporate social capital in the context of a law firm. His paper is concerned with how members of a collegial organization protect a fragile social mechanism - a 'lateral control regime'which is mobilized among peers to enforce previous agreements. He empirically documents a structure of lateral control that mainly reflects a specific firm protection strategy: oligarchs are divided into several subgroups, which are then selected to exercise control over each other. This evidence of an upward 'divide and rule' strategy is then presented as part of this firm's corporate social capital. 
In Type $\mathrm{D}$, organizations draw advantages from their own interorganizational networks. Joint venture relationships or joint marketing efforts, allowing for economies of scale or increased expertise, are examples of this type.

For example, Talmud et al. (2001) focus on network centrality and network cohesion characteristics of software startups firms in the fast growing high tech sector in Israel. They show how a corporate membership in a cohesive clique, being located at the center of an inter-organizational business network, is transformed into corporate social capital. A key position in a central clique of an inter-organizational network provides a corporate actor with a rent-seeking capacity enabling a business organization to extend its profitability, or to accrue valuable resources necessary for corporate success. Network centrality and geographical proximity in the relevant industry networks enables corporations to imitate 'successful' patterns of sense making and strategy formulation which is especially important due to the environmental conditions of severe uncertainty the software industry operates under. Strategic isomorphism is shown to be a necessary tool for navigating any meaningful purposive action, and for being recognized firms as a legitimate player by other firms.

Through interfirm relations, firms can gain timely and affordable access to new technology. Stuart (1999) shows, for example, how prestigious semiconductor firms establish license alliances in which they gain the rights to produce and sell the proprietary technologies of competing organizations. It is because of their ability to certify the initiatives of other organizations (especially, startups) that prestigious firm will gain access to the endeavors of others. The correspondence between prestige and access implies that prestigious firms enjoy a powerful positional advantage.

Harland and Knight (2001) apply a corporate social capital framework to the study of supply networks. While most studies on supply networks focus on manufacturing situations, which tend to concentrate more on tangible features of supply, their study analyzes the public sector. They conclude that taking a corporate social capital perspective of supply strategy helps 'socialize' the examination of supply networks in a 
way that existing operations management / supply based approaches do not. They argue that this is in particular the situation when socialization appears to be important in understanding public sector service situations. They find that there is some consonance between the corporate social capital framework of resources, social structure and goal attainment, and the input/ process/ output based models in operations management, thereby potentially easing its introduction to this field of application. Furthermore, taking a corporate social capital perspective enhances operations practitioner understanding of the complex supply situations in which they work; during the research these practitioners adopted the framework and language of corporate social capital in their analysis and in their communication with each other.

Recently, the research agenda has begun to shift to the strategic management of corporate social capital. Once the advantages of particular social structures in particular organizational settings have been uncovered, one can attempt to strategically manage beneficial structures. This line of work has very recently developed, mainly in the strategic management literature, and combines social capital and network research with strategic management theories (Gulati, 1999; Gulati, et al., 2000; Fiegenbaum et al., 2000).

\section{Conclusion}

Social capital in general and the study of social capital in the context of organizations has gained considerable attention in recent years. Despite the promise in the potency of the concept, its useful application suffers from the plethora of different definitions and approaches - both theoretical and empirical. In this paper we have built upon one unifying definition and attempted to provide an encompassing framework for corporate social capital - from both a theoretical and empirical point of view. If social capital research is to gain and maintain a strong and prominent foothold in the research of organization, the concept has to be founded in a framework, which is clear and 
unambiguous and flexible at the same time. We believe that the framework laid out in this paper may fulfill these requirements. 


\section{References}

Adler P. S., and S. Kwon. 2000. 'Social Capital: The Good The Bad and The Ugly.' In Lesser E. L., (Ed.) Knowledge and Social Capital: Foundations and Applications. Boston, Butterworth Heinemann.

Baker, W. E. (1984). The Social Structure of a National Securities Market. American Journal of Sociology 89: 775-811.

Baker, W. E. (1990). Market Networks and Corporate Behavior. American Journal of Sociology 96: 589-625.

Bourdieu, P. 1985. The Forms of Capital. In: J. G. Richardson (Ed.), Handbook of Theory and Research for the Sociology of Education (pp. 241-258). New York: Greenwood.

Boxman, E. A., De-Graaf, P. M. and Flap, H. D. 1991. The Impact of Social and Human Capital in the Income Attainment of Dutch Managers. Social Networks 13: 51-73.

Burt, R. S. 1982. Toward a Structural Theory of Action. New York: Academic Press.

Burt, R. S. (1992). Structural Holes: The Social Structure of Competition. Cambridge, MA: Harvard University Press.

Burt, R. S. (1997). 'The Contingent Value of Social Capital.' Administrative Science Quarterly 42: 339-365.

Burt, R. S. (2000). 'The Network Structure of Social Capital.' Research in Organizational Behavior 42: 339-365.

Burt, R. S., Gabbay S. M., G. Holt and P. Moran. (1994). 'The Culture-Performance Contingency Function.' Acta Sociologica 37: 345-370.

Coleman, J.S. (1988). 'Social capital in the creation of human capital', American Journal of Sociology 94: 95-120. 
Coleman J.S. (1990). Foundations of Social theory, Cambridge, MA: Belknap Press of Harvard University Press.

Davis, K. \& J.W. Newstrom, 1985, Human Behavior at Work: Organization Behavior (7th Ed.). New York: McGraw-Hill.

De Graaff, N. D. and H. D. Flap. (1988). With a little Help from My Friends. Social Forces. 67: 453-472.

Durkheim E. (1950). The Rules of Sociological Method. New York, the Free Press

Durkheim E. (1951). Suicide. New York, The Free Press

Fiegenbaum, A., Gabbay S. M., Bar-Am E. and R. Th. A. J. Leenders (2000).

Competitive Strategy and Corporate Social Capital: High Technology Spin-offs out of Elite Units in the Israeli Defense Forces' Paper presented at the Strategic Management Society 20th Annual International Conference, Vancouver, British Columbia, Canada

Gabbay, S.M. (1997). Social Capital in the Creation of Financial Capital: The Case of Network Marketing. Illinois: Stipes Publishing.

Gabbay, S.M. and Leenders, R. Th. A. J. (1999). CSC: The Structure of Advantage and Disadvantage. In R.Th.A.J. Leenders and S.M. Gabbay (Eds.), Corporate Social Capital and Liability (pp. 1-14). Boston: Kluwer Academic Publishers.

Gabbay S. M. and Ezra Zuckerman. (1998). 'Social Capital and opportunity in Corporate R\&D: The Contingent effect of contact density on mobility expectations. 'Social Science research 27: 189-217.

Gabbay S. M. and A. J. Stein (1999). Embedding social structure in Technological Infrastructure: Constructing Regional Social Capital for a sustainable peace in the Middle East.' In J. Wright (Ed.), The political economy of Middle East Peace (pp. 154-180). Boston and London: Routledge. 
Gabbay, S. M., Talmud I., and O. Raz (2001). 'Corporate social capital and corporate strategy: The case of Israeli high-technology start-ups' Research in the Sociology of Organizations, 18: 135-150.

Gargiulo, M. and M. Benassi. 1999. The Dark Side of Social Capital. In R.Th.A.J. Leenders and S.M. Gabbay (Eds.), Corporate Social Capital and Liability (pp. 298-322). Boston: Kluwer Academic Publishers.

Granovetter, M. 1973. 'The Strength of Weak Ties'. American Journal of Sociology 78: 1360-1380.

Granovetter, M. 1985. 'Economic Action and Social Structure: The Problem of Embeddedness'. American Journal of Sociology 91: 481-510.

Greve, A. and Saloff. (2001). 'The development of corporate social capital in complex innovation processes.' Research in the Sociology of Organizations 18: 107-134.

Gulati, R. 1999. Network Location and Learning: The Influence of Network Resources and Firm Capabilities on Alliance Formation. Strategic Management Journal 20: 397-420.

Gulati, R., Nohria, N. \& A. Zaheer. 2000. 'Strategic Networks.' Strategic Management Journal 21: 203-215.

Han, S. (1994). 'Mimetic Isomorphism and its effect on the Audit Services Market.' Social Forces 73: 637-663.

Hansen, M. T. Podolny J. M. and Jeffery Pfeffer. (2001). 'So Many Ties, So Little Time: A Task Contingency Perspective on Corporate Social Capital.' Research in the Sociology of Organizations 18: 21-57.

Harland C. and L. Knight, 2001. ' Supply strategy: A corporate social capital perspective' Research in the Sociology of Organizations 18: 151-183. 
Johanson J. (2001). 'The balance of corporate social capital: network cohesion as a determinant of instrumental and expressive benefits in a public organization.' Research in the Sociology of Organizations 18: 231-261.

Knoke D. (1999). Organizational Networks and Corporate Social Capital. In Leenders, R.Th.A.J. and S.M. Gabbay (Eds.). Corporate Social Capital and Liability (pp. 14-42). Boston: Kluwer Academic Press.

Krackhardt, D. and R. Stern. 1988. Informal Networks and Organizational Crisis: An Experimental Simulation. Social Psychology Quarterly 51:123-140.

Krackhardt, D. (1992). 'The Strength of Strong ties: The Importance of Philos in Organizations.' Pp. 216-239. In Networks in Organizations, N. Nohria and R. G. Eccles. Boston, MA: Harvard business School Press.

Kratzer, J. J., M. L. Van Engelen and R. Th. A. J. Leenders (1988). 'Structuring the Communication Infrastructure of Innovation Teams for Success.' Journal of Product Innovation Management. Conference Proceedings Series 9: 43-56.

Lazega E. (1999). Generalized Exchange and Economic Performance: Social Embeddedness of Labor Contracts in a Corporate Law Firm. In R.Th.A.J. Leenders and S.M. Gabbay (Eds.), Corporate Social Capital and Liability (pp. 237-265). Boston: Kluwer Academic Publishers.

Leenders, R. Th. A. J. (1995). 'Models for Network Dynamics: A Markovian Framework.' Journal of Mathematical Sociology 20: 1-21

Leenders, R. Th. A. J. (1997). Evolution of Friendship and Best Friendship Choices. Journal of Mathematical Sociology 21: 133-148.

Leenders, R.Th.A.J., \& S.M. Gabbay (Eds.). (1999a). Corporate Social Capital and Liability. Boston: Kluwer Academic Press.

Leenders, R.Th.A.J., \& S.M. Gabbay 1999b. 'CSC and Agenda for the future.' In Leenders, R.Th.A.J. \& S.M. Gabbay (Eds.). Corporate Social Capital and Liability. Boston: Kluwer Academic Press. 
Lin, N., W. M. Ensel, and J. C. Vaughn. (1981). 'Social Resources and Occupational Status.' Social Forces 59:4: 1163-1181.

Lin, N., W. M. Ensel, and J. C. Vaughn. (1981b). 'Social Resources and Strength of Ties.' American Sociological Review 46: 393-405.

Marsden, P. V., and J. S. Hulbert. 1988. Social Resources and Mobility Outcomes: a Replication and Extension. Social Forces 67:1038-1059.

Mizruchi, Mark S. and Lisa C. Fein, (1999). 'The Social Construction of Organizational Knowledge: A Study of the Uses of Coercive, Mimetic, and Normative Isomorphism,' Administrative Science Quarterly 44:653-683.

Nahapiet, J., \& Ghoshal, S. (1998). 'Social Capital, Intellectual Capital, and the Organizational Advantage.' Academy of Management Review 23: 242-266.

Nohria, N., and Eccles, R. G. (1992). Networks and Organizations. Boston: Harvard Business School Press.

Pennings, J. M. and L. Kyungmook. (1999). Social Capital of Organization: Conceptualization, Level of Analysis, and Performance Implications. In R.Th.A.J. Leenders and S.M. Gabbay (Eds.), Corporate Social Capital and Liability (pp. 298-322). Boston: Kluwer Academic Publishers.

Podolony, J. M. and James N. Baron. (1997). 'Relationship and Resources: Social Networks and Mobility in the Workplace.' American Sociological Review 62: 673-693.

Portes, A. and J. Sensenbrenner. (1993). 'Embeddedness and immigration: Notes on social determinants of economic action.' American Journal of sociology 98: 1320-1350.

Putnam R. D. (1993). 'The prosperous Community: Social Capital and Public Life. American Prospect 13: 35-42.

Salancik, G.R. 1995. Wanted: A Good Network Theory of Organization. Administrative Science Quarterly, 40: 345-349. 
Simmel, G. (1950). The Sociology of George Simmel. Edited and translated by Kurt Wolff. Glencoe Ill.: The Free Press.

Simmel, G. (1955). Conflict and the Web of Group Affiliations. New York: Free Press.

Simmons, D.B., 1985, 'The Nature of the Organizational Grapevine.' Supervisory Management Nov.: 39-42.

Snijders, T.A.B., 1996, 'Stochastic Actor-Oriented Dynamic Analysis.' Journal of Mathematical Sociology 21: 149-172.

Stuart T. (1999). Technological Prestige and the Accumulation of Alliance Capital. In Leenders, R. Th. A. J. and S. M. Gabbay (Eds.). Corporate Social Capital and Liability (376-389). Boston: Kluwer Academic Press.

Talmud, I. (1999). Corporate Social Capital and Liability: A Conditional Approach to Three Consequences of Corporate Social Structure. In Leenders, R. Th. A. J. and S.M. Gabbay (Eds.). Corporate Social Capital and Liability (pp. 106-117). Boston: Kluwer Academic Press.

Yasuda, Y. (1993). A Comparative Structural Analysis of American and Japanese Markets. Unpublished doctoral dissertation, Columbia University, New York.

Uzzi, B. 1997a. ' Social Structure and Competition in Interfirm Networks: The Paradox of Embeddedness.' Administrative Science Quarterly 42:35-67.

Uzzi, B.1997b. 'A Structural Embeddedness Approach to Deindustrialization and Organizational Decline.' The International Journal of Sociology and Social Policy 17: 111-155.

Wasserman, S. and K. Faust. (1994). Social Network Analysis: Methods and Applications. New York: Cambridge University Press.

Woolcock, M. 1998. Social Capital and Economic Development: Toward a Theoretical Synthesis and Policy Framework' Theory and Society 27: 151-208. 
Zeggelink, E. P. H. (1994). Dynamics of Structure: An Individual Oriented Approach. Social Networks 16: 295-333. 
FIGURE 1, Generic Structures of Social Capital

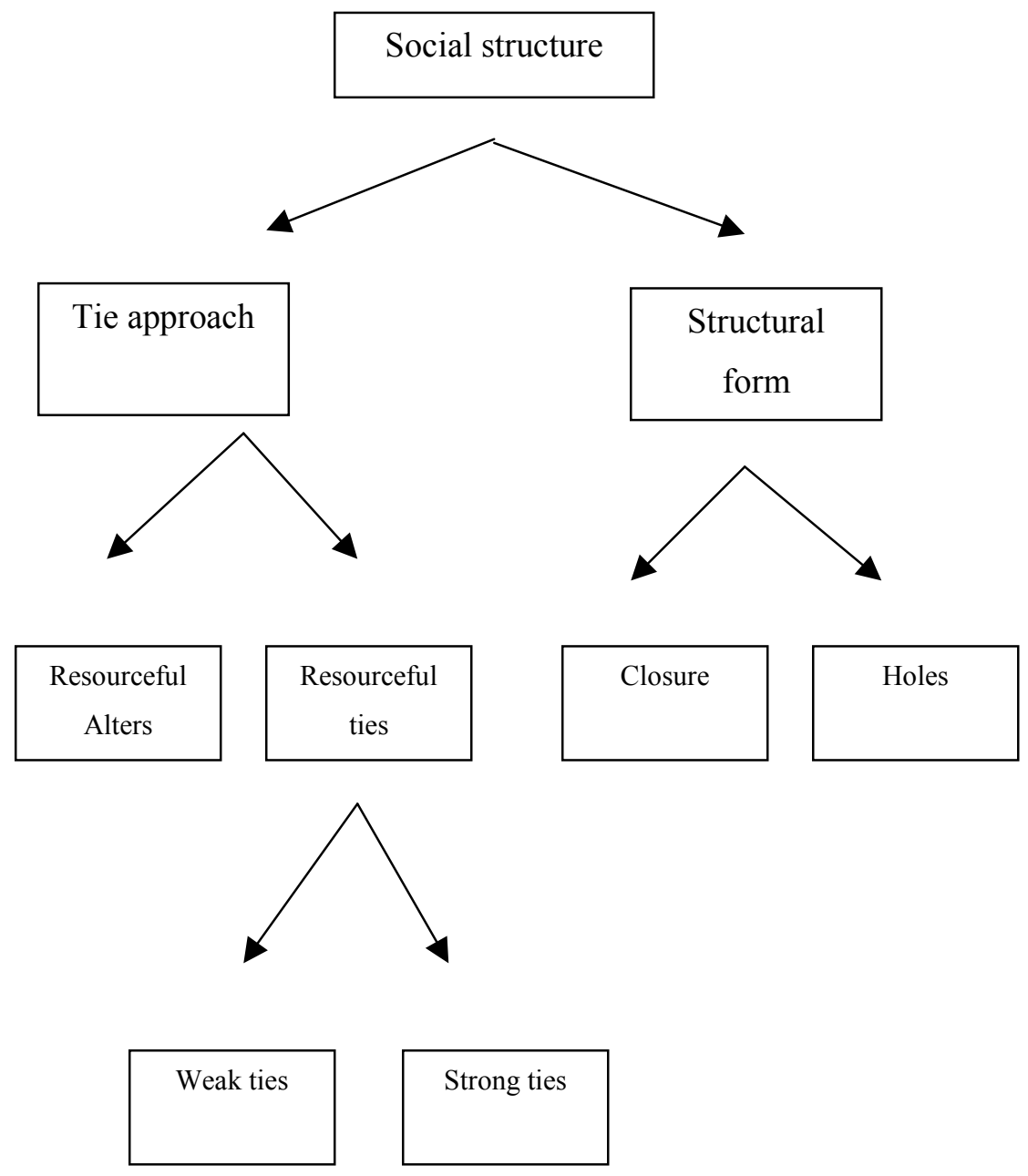


Figure 2, Coupling of both research approaches

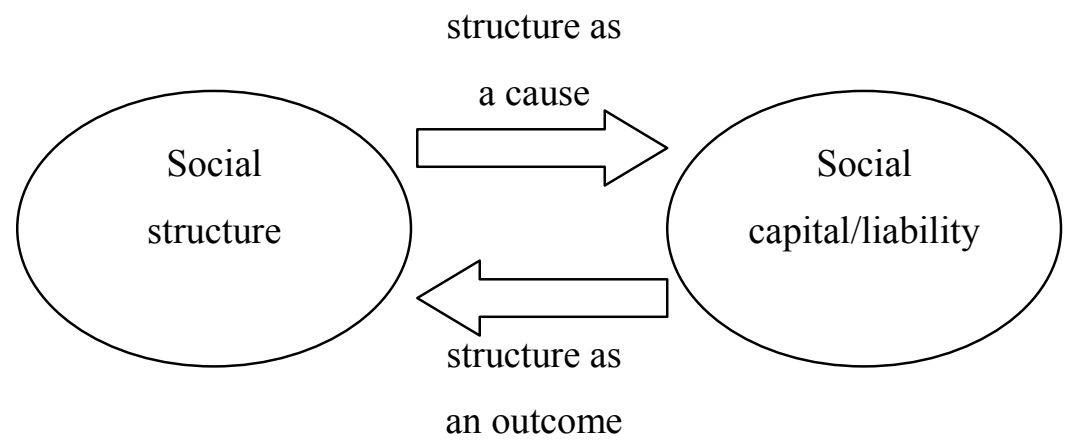


Figure 3, Structural causes of social capital and social liability at various levels of analysis

Social structure

Social capital/liability

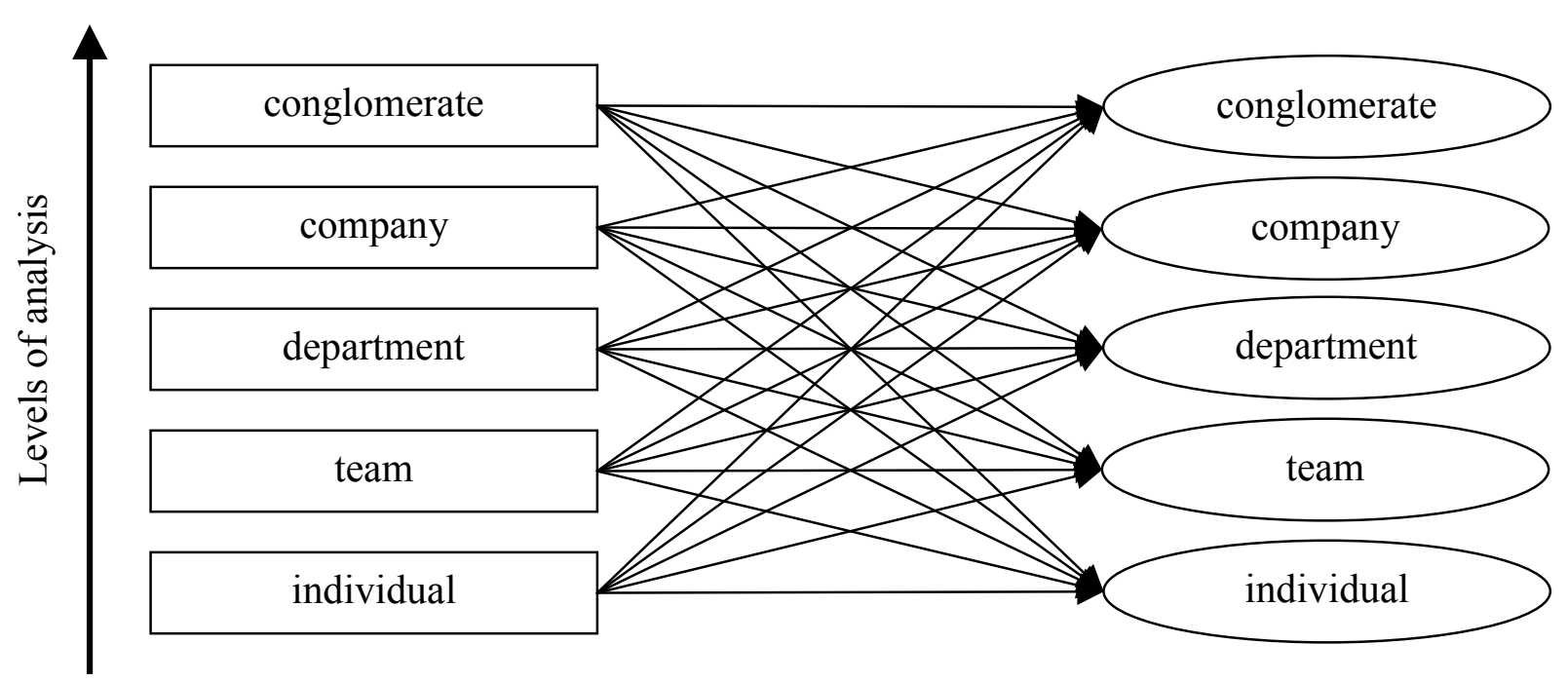


Figure 4, Interplay of levels of analysis

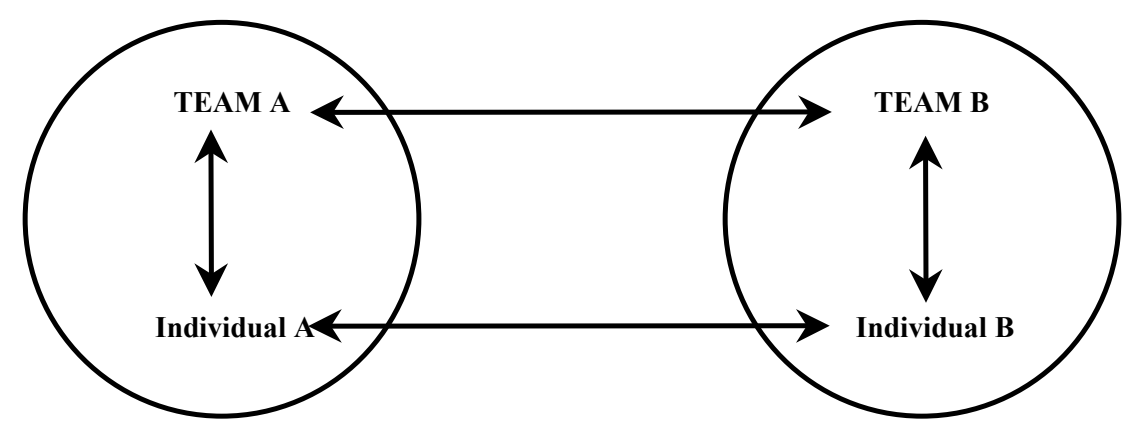


FIGURE 5, Levels of social structure and corporate social capital

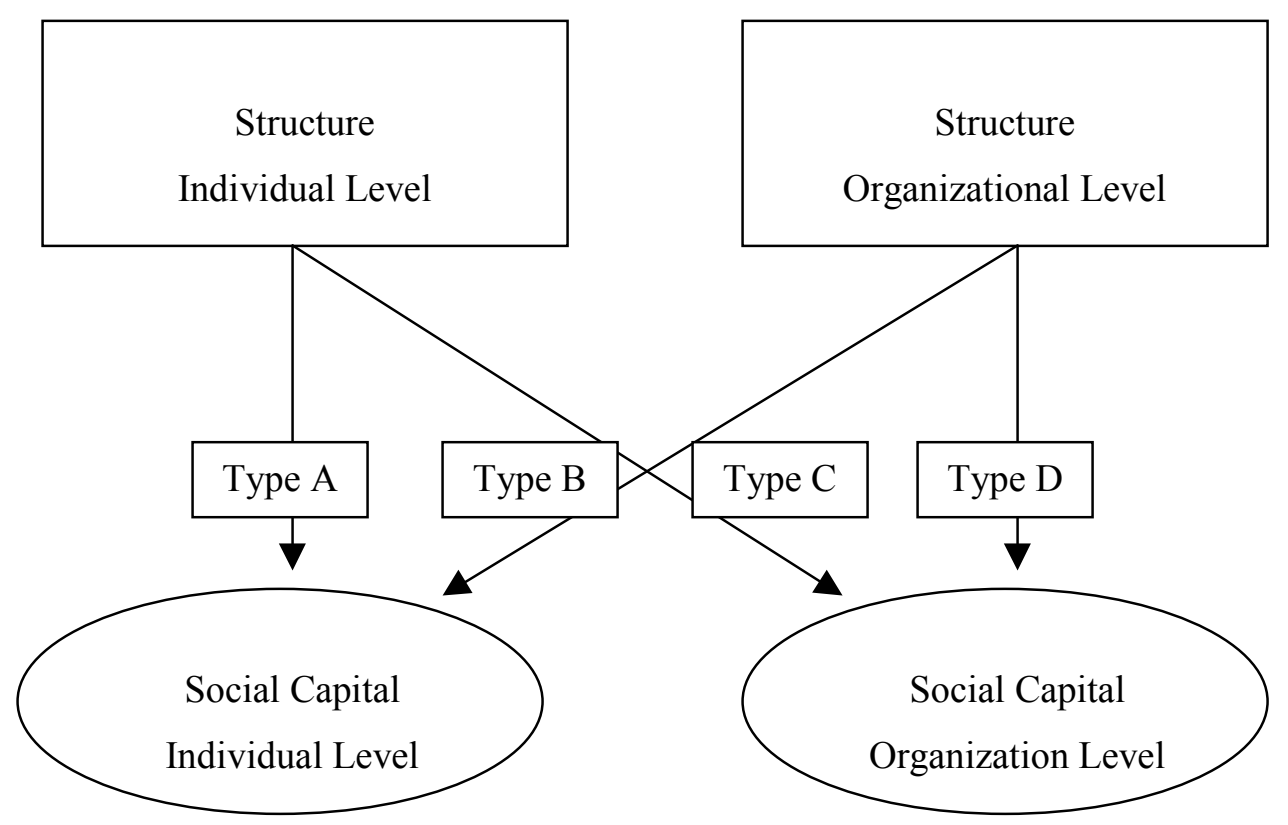

